\title{
A Framework for Mixed-method Research
}

\author{
Sindhu Shantha Nair
}

Christ University, Bangalore, Karnataka, India

\section{OPEN ACCESS}

Manuscript ID:

MGT-2020-08023220

Volume: 8

Issue: 2

Month: October

Year: 2020

P-ISSN: 2321-4643

E-ISSN: 2581-9402

Received: 14.08.2020

Accepted: 22.09.2020

Published: 01.10.2020

Citation:

Nair, Sindhu Shantha, and Smritika S. Prem. "A Framework for Mixedmethod Research." Shanlax International Journal of Management, vol. 8, no. 2, 2020, pp. 45-53.

DOI:

https://doi.org/10.34293/ management.v8i2.3220

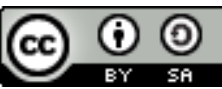

This work is licensed under a Creative Commons Attribution-ShareAlike 4.0 International License.

\section{Smritika S Prem}

Canada

\begin{abstract}
This article presents the basics of mixed-method research as a distinct methodology that uses both quantitative and qualitative research methods to create empirical research. The method of this study is a review. Through a substantive review, this paper explains the basic idea of a mixedmethod approach. The article identifies the main components of the mixed-method approach, provides examples, and describes how to conduct mixed-method research. A quantitative study involves collecting, identifying, and analyzing data. A qualitative study uses interviews or focus groups. An integration of both approaches helps a better understanding of the issue. This study brings out the role of mixed-method research to assess further approaches in future research practices. The combination of qualitative and quantitative research will enable a broader reach in empirical studies.
\end{abstract}

Keywords: Mixed-Method, Quantitative Study, Qualitative Method and Framework

\section{Introduction}

The mixed-method research is a distinctive form of research method using both quantitative and qualitative research methods so that strong empirical evidence is obtained. Mixed-method research is carried out on dynamic and unique topics or emerging topics. Qualitative research methods had arisen from sociology and anthropology. Researchers used to study people, social relationships, institutional relationships, and culture by using observations, archived secondary data, or interviews, describe them through the patterns that emerged from the data using clear ontology and epistemology. Quantitative research methods are descriptive study (survey methods through questionnaires), correlational study, causal-comparative study, quasiexperimental and experimental studies. Mixed-method of quantitative and qualitative approaches helps the researcher to gain a deeper understanding and confirmation while enabling the elimination of the weakness of each study if carried out in silos. Another advantage of conducting a mixed-method is that triangulation in terms of data, method, or researches is possible. Triangulation enables the researcher to have multiple perspectives of an occurrence through different techniques more accurately. The mixed-method can be used to corroborate results, clarify findings, to develop a theory, and test it, or to generalize findings from both the approaches. Thus mixed-method research provides strength, complete understanding, context specificity, and causal processes in a way that is better that when carried out using a quantitative study or a qualitative approach alone. This study provides a framework for mixed-method research. 


\section{Qualitative Research}

The qualitative research method inquires the sample under consideration through an in-depth inquiry into peoples' experiences, personal stories, or specific purposes. Qualitative research, in its broader perspective, tries to understand, interrogate, and deconstruct (Lather, 1991). Lather (1991) has not specified the need for prediction or generalization; In 'understand,' qualitative research gathers the required information based on someone's' experiences and reports. In 'interrogate,' qualitative research presumes that the experience is rested upon gender, age, race or sexuality, or any identity form and highlighted for inequalities and marginalization. In 'deconstruct,' qualitative research intends mostly to break stereotypes, social conditioning.

A qualitative researcher explores and understands in-depth, interrogate differences or deconstruct conditions and need not generalize. The examples given in Table 1 depicts why, in some cases, generalization is not required. Studies focused on a few attributes, or a social cause or social rationale, gender inequality are some to name.

Table 1: Examples of qualitative studies

\begin{tabular}{|l|l|c|c|}
\hline \multicolumn{1}{|c|}{ Research } & \multicolumn{1}{|c|}{ Sample } & Type of Study & $\begin{array}{c}\text { Generalization } \\
\text { needed? }\end{array}$ \\
\hline The Attitude of breast cancer patients in the second stage & Women in X city & Understand & No \\
\hline Gender sensitivity in Organization Y & $\begin{array}{l}\text { Employees in } \\
\text { Organization Y }\end{array}$ & Interrogate & No \\
\hline Social conditioning of Patriarchy in the village Z & Women in village Z & Deconstruct & No \\
\hline
\end{tabular}

Source: Author's elaboration

Based on the purpose, the ontology, epistemology, methods, and representation, the researcher has to wisely and sensibly decide based on the questions, methods, and analysis.

\section{Various Categories of Qualitative Research Studies}

There are different types of qualitative research inquiry for research and theories to support it. The basic outline of quantitative research inquiry is in Table 2 .

Table 2: Qualitative Research Inquiry purpose and Outline

\begin{tabular}{|l|l|l|}
\hline \multicolumn{1}{|c|}{ Understand } & \multicolumn{1}{|c|}{ Interrogate } & \multicolumn{1}{c|}{ Deconstruct } \\
\hline Interpretivism & Feminism & Postcolonial \\
\hline Narrative Inquiry & Marxism & Poststructural \\
\hline Phenomenology & Critical Theory & Diaspora \\
\hline
\end{tabular}

Source: Lather (1991), Getting Smart: Feminist

Research and Pedagogy with/in the postmodern, cited by Bhattacharya (2017)

Some of the categories of qualitative research studies are studies based on 'Interviews,' 'Narrative Inquiry,' 'Phenomenology,' 'Grounded Theory,' 'Case Study,' 'Ethnography,' Auto-ethnography,' and 'Critical ethnography,' 'Art-based approach,' and 'Oral History.'
In the Interview study, the inquiry approach is the interview, and the different modes are openended interviews, closed-ended interviews, depth interviews, critical incident interviews, and feminist interviews depending upon the purpose of the inquiry. Some of the prominent works in interview methods are from Spradley (1979), DeMarris (2004), Kvale, and Brinkman (2009). In Narrative Inquiry, a researcher tries to understand the study sample and narrate their experience in the modal of a story. The seminal work in the narrative inquiry was by Polkinghorne (1989), and a few other authors are Clandinin (2007) and Kim (2006). In qualitative studies, one of the most used categories is Phenomenology, rooted in philosophy uses reflection on experiences of participants as part or the whole experience of an event. This category is used in exploratory studies, or to articulate a phenomenon which is shared, to understand the experience structure to help the abstraction of the quintessence of the experience. The seminal work in phenomenology was by Husserl (1931), and a few other authors are Elveton (2003), von Herrmann (2013), and Manen (2014). Grounded Theory is a process of inquiry used by researchers to develop a theory rooted in-depth in a structure and system. Whether this approach should be with prior 
experience of the researcher or based on literature is debated upon to date. Generally, the objectivist approach presumes the researcher with less predecided data.

In contrast, the constructivist approach urges the researchers to develop their construction of meaning based on the interaction from different sources of participants and data sets. The seminal finding of grounded theory was from Glaser and Strauss (1967), and some other prominent works are from Strauss and Corbin (1998) and Charmaz (2006). The Case Study approach is the analysis of a place, situation, people, issue, success, or failure factors of an organization or business, psychological issues predetermined for the study. This approach makes the concepts clear to the researchers and the readability of the cases. The researcher has to draw boundaries to define the situation. The seminal work on a case study was from Stake (1995), and some other prominent works are from Yin (2003, 2006); Hancock \& Algozzine (2006).

Ethnography is an approach through which people and culture are studied for a long time about their way of life, activities, interests, habits, food habits, languages, ongoing phenomenon, social occasions through interviews, documentation, collecting materials from them in the best possible way. Few works on ethnography are from Lecompte and Preissle (1993), Van Mannen (1988), and Wolcott (2008). Auto-Ethnography is an approach of self-reflection of experiences in analysis with the researcher's context of occurrence of similar experiences. Often this helps in a deeper understanding of depression, social structures, social justice, and documentation. Thus auto-ethnography is a combination of the auto (self-biography) and ethnic (race, culture; ethnicity: human beings) graphics (representing). Some of the works in auto- ethnography are from Ellis and Bochner (1996), Ellic (2004), Jones, Adams, and Ellis (2013). Critical ethnography is an ethnographic study wherein the people, race, culture, or societies are critically cross-examined and interrogated to bring out the structures of inequality through interactions. Some of the works of critical ethnography are by Thomas (1993), Carspecken (1995), and Madison (2005). The art-based approach employs the tenets of creative arts to arrive at an artistic representation (dramatic, poetic, pictures, photos) of findings. Much eminent work of art-based approach is Knowles and Cole (2007), Barone and Eisner (2012), and Leavy $(2008,2015)$. Oral history, is a way of storytelling or story narration of individuals, community, or society propending inequalities, social justice, gender sensitivity, existential pain, distress, or hardships. Few examples are the story of Holocaust survivors, flood victims, women oppressed by toxic masculinity, child abuse, or rape victims. The eminent works for oral history are Perks, and Thomson $(1998,2006)$, Janesick (2010), Leavy (2011).

\section{Philosophical Concept}

The philosophical concept for research is positivism, post-positivism, phenomenology, critical theory, feminism, etc.

\section{Positivism Paradigm and Applicability}

Positivism is the consideration of that which is scientific and empirically verified with logical proof. Auguste Comte (1789-1857) coined positivism, arguing that research ought to progress from theism and metaphysics to a positivistic approach with dominant scientific inquiry, positive assertion of theories from the scientific method. The accuracy and certainty of scientific inquiry assumptions surged in 1990 with mathematical functions and operations (Crotty, 1998).

\section{Post Positivism}

It is interesting to note that positivism considered the research and the researcher not to be dependent, post-positivism supposed that the observations are influenced by the background knowledge, theories, and the researcher's values. Seminal work on postpositivism was by Sir Karl Popper (1934), who contended falsification against the verification of positivism and stated that unobservable truths or beliefs are non-verifiable. Still, at the same time, the possibility to reject false beliefs provided the phrasing has the flexibility of falsification. Kuhn provided a paradigm shift to positivism logic, explaining that not only individual theories but also world views ought to reposition, displace, or switch with evidence. While post-positivism does not reject scientific evidence, it reforms positivism to 
reinvent the positivist approach and assumptions of objectivism and methodological experiments, which is in social sciences.

\section{Interpretivism}

The philosophy of Interpretivism emerged from the critique of positivism on reality through social constructions of shared meanings, instruments, consciousness, or language (Myers, 2008). Idealism is the philosophical emphasizing in Interpretivism and aligns the diversity in approaches such as constructivism, phenomenology, and hermeneutics. Interpretivism appreciates differences between people, focuses on the meaning, and the methods used are multiple to bring out the various aspects.

\section{Interpretivism Approaches}

1. Phenomenology is the philosophy that tries to understand a phenomenon of the past through experiences and find new ways to understand that experiences from new insights (Crotty, 1998)

2. Hermeneutics is the philosophy of interpretation and understanding, mostly used to interpret and understand biblical texts.

3. Symbolic interactionism is the philosophy that tries to understand the objects through shared meanings using symbols to construct reality.

The difference between positivism and Interpretivism (Pizam and Mansfeld, 2009) is in Table 3.

Table 3: The Difference between Positivism and Interpretivism

\begin{tabular}{|l|l|l|}
\hline Assumption & Positivism & Interpretivism \\
\hline Focus & $\begin{array}{l}\text { General, average, } \\
\text { and representative }\end{array}$ & $\begin{array}{l}\text { Specific, unique } \\
\text { and deviant }\end{array}$ \\
\hline
\end{tabular}

\begin{tabular}{|l|l|l|}
\hline $\begin{array}{l}\text { Knowledge } \\
\text { created }\end{array}$ & $\begin{array}{l}\text { Absolute (time, } \\
\text { context and value- } \\
\text { free) }\end{array}$ & $\begin{array}{l}\text { Relative (time, } \\
\text { context, culture } \\
\text { and value } \\
\text { bound) }\end{array}$ \\
\hline $\begin{array}{l}\text { Researcher } \\
\text { relationship }\end{array}$ & Rigid & $\begin{array}{l}\text { Interactive/ } \\
\text { participative/ } \\
\text { cooperative }\end{array}$ \\
\hline Reality & $\begin{array}{l}\text { Objective/ } \\
\text { tangible/single }\end{array}$ & $\begin{array}{l}\text { Socially } \\
\text { constructed, } \\
\text { multiple }\end{array}$ \\
\hline $\begin{array}{l}\text { Research } \\
\text { Goals }\end{array}$ & $\begin{array}{l}\text { Strong prediction } \\
\text { or explanation }\end{array}$ & $\begin{array}{l}\text { Understanding, } \\
\text { weak prediction }\end{array}$ \\
\hline Information & $\begin{array}{l}\text { The 'how' of } \\
\text { People thought } \\
\text { process of a } \\
\text { specific problem }\end{array}$ & $\begin{array}{l}\text { 'what' do } \\
\text { people think of } \\
\text { a problem and } \\
\text { to solve it }\end{array}$ \\
\hline
\end{tabular}

Source: Positivism versus Interpretivism; Pizam and Mansfeld (2009)

Critical theories focus on social structures and their experiences, inequities, oppressive discourses, social injustices, basically for human liberation. The school of thought is developed by Horkheimer (1982). Feminism is on the tenets of equality in society. Also to fight against broad forms of generalized inequality like oppressing women, unequal rights, opportunities,

\section{Qualitative Techniques}

The research methodology or methodological inquiry for qualitative research using narratives, phenomenological inquiry, grounded theory inquiry, case study approach, or ethnographic inquiry is in Table 4.

Table 4: Qualitative Research Methodology

\begin{tabular}{|c|c|c|c|c|}
\hline Narrative Inquiry & $\begin{array}{c}\text { Phenomenological } \\
\text { inquiry }\end{array}$ & $\begin{array}{c}\text { Grounded } \\
\text { theory inquiry }\end{array}$ & Case Study & $\begin{array}{c}\text { Ethnographic } \\
\text { inquiry }\end{array}$ \\
\hline Thematic & Transcendental & Objectivist & Single instrumental & Realistic \\
\hline Biographical & Existential & Constructivist & Collective/Multiple & Critical \\
\hline Autobiographical & \multirow{4}{*}{ Hermeneutic } & & \multirow{4}{*}{ Intrinsic } & Virtual \\
\hline Life history & & & & Digital \\
\hline Oral history & & & & Visual \\
\hline Art-based & & & & \\
\hline
\end{tabular}

Source: Fundamentals of Qualitative Research, Bhttacharya (2017) 


\section{Data Collection Methods}

In the Interview method, the researchers often use conversations, casual interactions, critical interactions, etc. to understand the experience, situation, the topic of concern or a problem through formal semi-structured interviews, depth, and openended interviews, informal open-ended interviews, or natural conversations (Bhattacharya, 2017).

The types of interview questions are in Table 5.

Table 5: Types of Interview Questions

\begin{tabular}{|c|c|c|c|c|c|c|}
\hline $\begin{array}{c}\text { Descriptive } \\
\text { questions }\end{array}$ & $\begin{array}{c}\text { Grand Tour } \\
\text { questions }\end{array}$ & $\begin{array}{c}\text { Specific } \\
\text { Grand Tour } \\
\text { questions }\end{array}$ & $\begin{array}{c}\text { Task- related } \\
\text { Grand Tour } \\
\text { questions }\end{array}$ & $\begin{array}{c}\text { Mini Tour } \\
\text { questions }\end{array}$ & $\begin{array}{c}\text { Structural } \\
\text { questions }\end{array}$ & $\begin{array}{c}\text { Critical } \\
\text { questions }\end{array}$ \\
\hline $\begin{array}{c}\text { Generate } \\
\text { information } \\
\text { about a specific } \\
\text { incident with } \\
\text { details }\end{array}$ & $\begin{array}{c}\text { Generate details } \\
\text { about everyday } \\
\text { experiences } \\
\text { in a particular } \\
\text { situation }\end{array}$ & $\begin{array}{c}\text { Probing } \\
\text { specific } \\
\text { incident } \\
\text { and related } \\
\text { experiences }\end{array}$ & $\begin{array}{c}\text { Rooted in a } \\
\text { specific task } \\
\text { to generate } \\
\text { relevant } \\
\text { information }\end{array}$ & $\begin{array}{c}\text { For a } \\
\text { specific, } \\
\text { mini-unit of } \\
\text { experiences }\end{array}$ & $\begin{array}{c}\text { To } \\
\text { understand } \\
\text { the structure } \\
\text { of the } \\
\text { environment }\end{array}$ & $\begin{array}{c}\text { To disprove } \\
\text { some salient } \\
\text { experience of } \\
\text { participants. }\end{array}$ \\
\hline
\end{tabular}

Source: Fundamentals of Qualitative Research, Bhttacharya (2017)

In the Observation method, the researchers adopt participant observation (Dewalt and Dewalt, 2002) in the form of peripheral, active, or full membership. The process is to gain access and mutual benefit.

\section{Data Analysis in Qualitative Research Method}

The inductive analysis is used in qualitative research analysis, wherein inferences are from the data collected. The process does not relate to any assumed hypotheses. The researcher looks into the raw data, code the data (segregating into meaningful information or units), cluster the data, categorize, and identify the data into themes.

\section{Interpretation in Qualitative Research}

From the data analysis, narratives can be developed, from segmentation and units, re-analyzing and reflecting on the insights. The various types of representation in qualitative research are thematic, poetic, plays, performances, documentaries, musicals, novels, short stories, photo essays, digital stories, etc. (Bhattacharya, 2017).

\section{Quantitative Techniques}

The epistemology of quantitative research is positivism and post-positivism. The ontology specifies the phenomena and is measurable to understand (O'Dwyer and Bernauer, 2014). This background qualifies a quantitative study to be objectified and scientifically independent. The characters of investigation are the variables. For example, to analyze the role of mobile usage in student performance, the variables are mobile usage and student performance. Depending on the study criteria, the variables may be categorical (varies in type) or continuous (type and degree). Based on the topic of interest of the researcher, an issue or problem, the research questions arise, the concepts/ constructs identified from the premise of theoretical underpinnings, and variables of the study are determined. The variables are, in turn, operationalized. The stated research hypotheses are verified through empirical evidence and accepted or rejected.

The quantitative study can be experimental or otherwise. Experimental studies can be pure or quasi, based on the selection of the test and control groups. Non-experimental studies may be categorized into descriptive, predictive, explanatory, cross-sectional, longitudinal, and retrospective (O'Dwyer and Bernauer, 2014). The research design in quantitative research includes measurement, statistical analysis, and interpretation. Statistically, the study can be descriptive based on the predictive or explanatory nature of the study or inferential based on the generalizability of the study.

The quantitative research may be descriptive, explanatory, comparative, or case study. The Data in a quantitative approach is in numbers, which makes it easily computable, unlike the qualitative data expressed in words. This numbered data and computing makes the findings generalizable, repeated, or more reliable. Whereas to repeat the conversations or interviews or observation with the 
participants in the qualitative study and to get the data repeatedly are difficult. Existing instrument/s or a questionnaire is using techniques to survey the respondents in concern. This data is coded into numbers and analyzed using statistical analysis software; findings interpreted and is discussed for results and implications.

The quantitative approach is a broader study, and the qualitative method is an in-depth study (Figure 1). Qualitative research helps to seize the depth and diversity (Geertz, 2003).

Figure 1: Quantitative and Qualitative Research representation
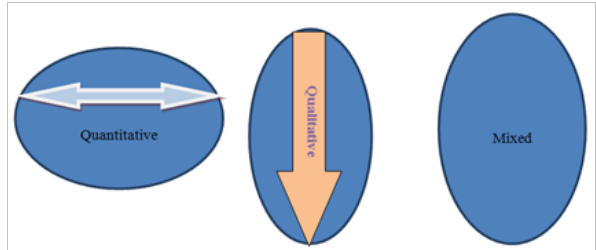

Source: adapted from Fundamentals of Qualitative Research, (Bhattacharya, 2017)

\section{Mixed-Method}

Research studies use both quantitative and qualitative methods to gather a holistic perspective of a phenomenon. For example, if research is about the trauma of cancer patients, the researcher may have to collect quantitative data from the selected community of cancer patients along with their age, marital status, financial security, family support, attitude to the health status. Nevertheless, qualitative data is also necessary to find their coping methods, the experience of diagnosis and treatment, how they perceive the family support, how they build resilience, etc. Brewer and Hunter (2005) posited that many researchers are using mixed-methods of quantitative and qualitative to minimize the gaps and widen the research advantages.

The advantage of the survey is that the participants can be surveyed even with the minimal personal involvement of the researcher. At the same time, observation or depth interviews call for the maximum collaboration between the researcher and the participant. At the same time, such observation and depth interviews can bring in substantial qualityelucidation and behavioral attributes from the respondents. Such an approach may later help to develop a theory.

\section{Mixed-method Advantages}

While qualitative research embraces the philosophical underpinnings explained in this article, there is differentiation among researchers about the different perspectives of the theoretical frameworks (Creswell, 2007). Moreover, the quantitative method, with its various designs based on the purpose of description, exploration, or explanation, does not comprise the philosophies or the diversity paradigms encompassed in the qualitative method. The authors do not negate the importance of each approach, either quantitative or qualitative, for the intended purpose of the research, keeping in mind that every study brings out the unknown or fills the gap in the existing knowledge through the researcher's perception, susceptibility, paradigmatic concerns. Nevertheless, the authors try to state that there is an apparent distinction between the quantitative and qualitative methods; thereby if used, one can complement the other to make the research holistic. "There is no inherent reason why either paradigm cannot accommodate, and be contributed to, by either methodology" (Guba, 1981, p.78). The shared differences in quantitative and qualitative methods were stated by O'Dwyer, and Bernauer (2014) as "qualitative research seeks to discover new knowledge by retaining complexities as they exist in natural settings, whereas quantitative research seeks to discover new knowledge by simplifying complexities in settings that tend to be more contrived."

The dichotomy between quantitative and qualitative methods need not deter a researcher's commitment to carry out quality work; as the Nobel prize winner Albert Szent-Gyorgyi (1893-1986) rightly posited, "Discovery consists of seeing what everybody has seen and thinking what nobody has thought." This argument raises the pertinent question of whether the research approaches of quantitative and qualitative characteristic is to solve problems or to find and solve problems. Walcott (1994, p.401) clearly states this dilemma as in "The idea that research is viewed as a problem setting, rather than problem-solving did not set too well when I first encountered it." Many times, researchers are diverted to the methodology to narrow down to a researchable problem that the incorporeal existence of potential 
SHANLAX

International Journal of Management sum

methods for myriad possibilities of quality research is overlooked.

The Framework of Empirical Inquiry for Quantitative and Qualitative Research is in Table 6.

Table 6: Framework of Inquiry

\begin{tabular}{|l|l|l|}
\hline & \multicolumn{1}{|c|}{ Qualitative } & \multicolumn{1}{|c|}{ Quantitative } \\
\hline Measurement & $\begin{array}{l}\text { Trustworthiness, } \\
\text { Credibility }\end{array}$ & $\begin{array}{l}\text { Validity, } \\
\text { Reliability }\end{array}$ \\
\hline Data & Words & Numbers \\
\hline Analysis & $\begin{array}{l}\text { Coding, Narrative } \\
\text { or both }\end{array}$ & Descriptive \\
\hline Process & Segmentation & Inferential \\
\hline
\end{tabular}

\begin{tabular}{|l|l|l|}
\hline Design & Interpretive & $\begin{array}{l}\text { Statistical } \\
\text { Analysis, } \\
\text { Interpretive }\end{array}$ \\
\hline Propensity & $\begin{array}{l}\text { Inductive } \\
\text { reasoning }\end{array}$ & $\begin{array}{l}\text { Deductive } \\
\text { Reasoning }\end{array}$ \\
\hline Approach & Systematic Rigor & Systematic Rigor \\
\hline Evaluation & $\begin{array}{l}\text { Categorizing, } \\
\text { Conceptualizing }\end{array}$ & $\begin{array}{l}\text { Statistical } \\
\text { Significance } \\
\text { and Effect Size }\end{array}$ \\
\hline Interpretation & $\begin{array}{l}\text { Based on facts } \\
\text { and findings }\end{array}$ & $\begin{array}{l}\text { Based on facts } \\
\text { and findings }\end{array}$ \\
\hline
\end{tabular}

The strength and limitations of Qualitative and Quantitative Research are in Table 7.

Table 7: Strength and Weakness of Qualitative and Quantitative Research

\begin{tabular}{|c|c|c|c|}
\hline \multicolumn{2}{|c|}{ Qualitative } & \multicolumn{2}{|r|}{ Quantitative } \\
\hline Strength & Weakness & Strength & Weakness \\
\hline $\begin{array}{l}\text { Substantial and deep } \\
\text { understanding of } \\
\text { complexities }\end{array}$ & Reflexivity & Objective framework & Objectivity \\
\hline Lived experiences & $\begin{array}{l}\text { Scarcity of quantitative } \\
\text { information }\end{array}$ & $\begin{array}{l}\text { Predict behaviors, cause } \\
\text { and effect relationships, } \\
\text { researcher controlled } \\
\text { experiments }\end{array}$ & $\begin{array}{l}\text { Context is Limited to address } \\
\text { research questions and objectives } \\
\text { only. }\end{array}$ \\
\hline $\begin{array}{l}\text { Art-based researches } \\
\text { help educators and } \\
\text { social sciences }\end{array}$ & & $\begin{array}{l}\text { Allow generalizations } \\
\text { (if samples are } \\
\text { representative) }\end{array}$ & $\begin{array}{l}\text { Generalizability limited to the } \\
\text { instruments, statistical tools, and the } \\
\text { representativeness of the sample. } \\
\text { Often generalizability is overstated. }\end{array}$ \\
\hline & $\begin{array}{l}\text { More time- consuming } \\
\text { in some researches }\end{array}$ & $\begin{array}{l}\text { Less time-consuming in } \\
\text { some researches }\end{array}$ & $\begin{array}{l}\text { The Hypothesis stating limits the } \\
\text { researcher to observe important } \\
\text { information, emerging ideas from } \\
\text { the study or theory formation } \\
\text { unless careful for mitigating such } \\
\text { weaknesses. }\end{array}$ \\
\hline
\end{tabular}

\section{Bringing together the Research}

Quantitative research focuses on the generalization of findings (external validity) across respondents, which is basically through representation from probability sampling. Qualitative research focuses on the description of respondents based on the situation, which may be transferable to several clusters. A mixed approach can bridge the gap between the studies. Both methods have unique roles and can complement each other. The differences can be used as strengths to understand the research in width and depth to bring out substantial new knowledge systematically without any boundaries between the quantitative and qualitative paradigms.

\section{Discussion}

The research world is very vast, and a prudent researcher has to carry out research in all possibilities rather than the easy way out or settle for less. There exists a multitudinous array of research problems in the natural world which, if it is researched, is very much self-fulfilling and benefitting the society at large. Whether the researcher has a qualitative inclination or quantitative, indulging in both to use a mixed-method of research will enable the researcher to engage in extensive research with distinct research focused tools, explore the phenomena of both quantitative and qualitative research methods (Gardner, 1983). Moreover, as mentioned by 
Vygotsky, the primal numbers in quantitative and words in qualitative methods for the same focus, to unearth renewed, refreshed, regenerated, or remodeled knowledge will produce improvised and creative discernment (Karpov \& Haywood, 1998). A mixed-Method study can augment and analyze complex problems through the utilization of both qualitative and quantitative methods. The purpose of the research decides the methods, whether it is explorative, explanatory, grounded theory, theory testing, or generalization. This article gives a basic frame work for understanding mixedmethod research and the advantages of using it. The disadvantages can be the complex research design, the time required for conducting both methods, resources required, integrating, and interpreting the findings. Despite any disadvantages mentioned, a mixed-method provides strength, comprehensive understanding, develop research instruments with better construct validity, causal processes, and develop a theory.

\section{Conclusion}

The combination of qualitative and quantitative research will enable a broader reach in empirical studies. While the quantitative research method will rise to scientific research, the qualitative research method is exploratory, providing the phenomenology, reasons, opinions, or motivations and may help to develop ideas or frame hypotheses for further quantitative research or complement or confirm the quantitative research. A combination of methods may also help in the gap analysis.

\section{References}

Barone, Tom, and Elliot W. Eisner. Arts-based Research, Sage Publications, 2011.

Bhattacharya, Kakali. Fundamentals of Qualitative Research, Routledge, 2017.

Brinkmann, Svend, and Steinar Kvale. InterViews: Learning the Craft of Qualitative Research Interviewing, Sage Publication, 2014.

Carspecken, Phil Francis. Critical Ethnography in Educational Research, Routledge, 1996.

Charmaz, Kathy. Constructing Grounded Theory: A Practical Guide through Qualitative Analysis, Sage Publications, 2006.
Clandinin, D. Jean, and Connelly, F. Michael. Narrative Inquiry: Experience and Story in Qualitative Research, Wiley, 2004.

Comte, Auguste. A General View of Positivism, translated by J. H. Bridges, Cambridge University Press, 2009.

Comte, Auguste. Cours de Philosophie Positive, Project Gutenberg.

Corbin, Juliet, and Anselm Strauss. Basics of Qualitative Research: Techniques and Procedures for Developing Grounded Theory, Sage Publications, 2014.

Crotty, Michael. The Foundations of Social Research: Meaning and Perspective in the Research Process, Sage Publications, 1998.

deMarrais, Kathleen. "Qualitative Interview Studies: Learning through Experience." Foundations for Research: Methods of Inquiry in Education and the Social Sciences, edited by Kathleen deMarrais and Stephen D. Lapan, Lawrence Erlbaum Associates, 2004, pp. 51-68.

Dewalt, Kathleen, M., and Billie R. Dewalt. Participant Observation: A Guide for Fieldworkers, Altamira Press, 2002.

Ellis, Carolyn, and Arthur P. Bochner. Composing Ethnography: Alternative Forms of Qualitative Writing, AltaMira Press, 1996.

Ellis, Carolyn. The Ethnographic I: A Methodological Novel about Autoethnography, Altamira Press, 2004.

Elveton, R.O. The Phenomenology of Husserl, Quadrangle Books, 1970.

Glaser, Barney G., and Anselm L. Strauss. The Discovery of Grounded Theory: Strategies for Qualitative Research, Aldine, 1967.

Hancock, Dawson R., and Bob Algozzine. Doing Case Study Research: A Practical Guide for Beginning Researchers, Teachers College Press, 2006.

Horkheimer, Max. Critical Theory: Selected Essays, Continuum International Publishing Group Ltd., 1975.

Husserl, Edmund. Ideas: General Introduction to Pure Phenomenology, Routledge, 2012.

Janesick, Valerie J. Oral History for the Qualitative Researcher: Choreographing the Story, Gulford Publications, 2010. 
Jones, Stacy Holman, et al. Handbook of Myers, Michael D. Qualitative Research in Business Autoethnography, Routledge, 2013. \& Management, SAGE Publications, 2009.

Kim, Jeong-Hee. "For Whom the School Bell Tolls: Conflicting Voices Inside an Alternative High School." International Journal of Education \& the Arts, vol. 7, no. 6, 2006, pp. 1-19.

Knowles, J. Gary, and Ardra L. Cole. Handbook of the Arts in Qualitative Research: Perspectives, Methodologies, Examples and Issues, Sage Publications, 2007.

Kuhn, Thomas. The Structure of Scientific Revolutions, University of Chicago Press, 1962.

Lather, Patricia. Getting Smart: Feminist Research and Pedagogy with/in the Postmodern, Psychology Press, 1991.

Leavy, Patricia. Method Meets Art: Arts-Based Research Practice, The Gullford Press, 2009.

Leavy, Patricia. Oral History: Understanding Qualitative Research, Oxford University Press, 2011.

LeCompte, Margaret, \& Judith Preissle. Ethnography and Qualitative Design in Educational Research, Emerald Group Publishing Limited, 1993.

Madison, Soyini. Critical Ethnography: Method, Ethics an Performance, Sage Publications, 2011.

Martineau, Harriet. The Positive Philosophy of Auguste Comte, AMS Press, 1977.

Miller, Katherine. Communication Theories: Perspectives, Processes and Contexts, McGraw-Hill, 2002.

Perks, Robert, and Alistair Thomson. The Oral History Reader, Routledge, 2015.

Polkinghorne, Donald E. "Phenomenological Research Methods." Existential Phenomenological Perspectives in Psychology, edited by Ronald S. Valle and Steen Halling, Springer, 1989, pp. 41-60.

Popper, Karl Raimund. Conjectures and Refutations: The Growth of Scientific Knowledge, Psychology Press, 2002.

Popper, Karl Raimund. The Logic of Scientific Discovery, Psychology Press, 2002.

Spradley, James P. The Ethnographic Interview, Holt, Rinehart and Winston, 1979.

Stake, Robert E. The Art of Case Study Research, Sage Publications, 1995.

Thomas, Jim. Doing Critical Ethnography, Sage Publications, 1992.

Van Maanen, John. Tales of the Field: On Writing Ethnography, University of Chicago Press, 1988.

Van Manen, Max. Phenomenology of Practice: Meaning-Giving Methods in Phenomenological Research and Writing, Routledge, 2016.

von Hermann, Friedrich-Wilhelm. Hermeneutics and Reflection: Heidegger and Husserl on the Concept of Phenomenology, University of Toronto Press, 2013.

Wolcott, Harry. Ethnography: A way of Seeing, Altamira Press, 1999.

Yin, Robert. Case Study Research: Design and Methods, Sage Publications, 2003.

\section{Author Details}

Sindhu Shantha Nair, Christ University, Bangalore, Karnataka, India, Email ID: sindhusonnet@gmail.com

Smritika S Prem, Canada, Email ID: smritika246@gmail.com 